Recent Applications of SPME in Directed Stockpile Work (FY04)

C. Alviso, C. Harvey, A. Vance

November 9, 2004 
This document was prepared as an account of work sponsored by an agency of the United States Government. Neither the United States Government nor the University of California nor any of their employees, makes any warranty, express or implied, or assumes any legal liability or responsibility for the accuracy, completeness, or usefulness of any information, apparatus, product, or process disclosed, or represents that its use would not infringe privately owned rights. Reference herein to any specific commercial product, process, or service by trade name, trademark, manufacturer, or otherwise, does not necessarily constitute or imply its endorsement, recommendation, or favoring by the United States Government or the University of California. The views and opinions of authors expressed herein do not necessarily state or reflect those of the United States Government or the University of California, and shall not be used for advertising or product endorsement purposes.

This work was performed under the auspices of the U.S. Department of Energy by University of California, Lawrence Livermore National Laboratory under Contract W-7405-Eng-48. 


\title{
Recent Applications of SPME in Directed Stockpile Work (FY04)
}

\author{
Cindy Alviso, Chris Harvey \& Andrew Vance \\ Lawrence Livermore National Laboratory \\ Livermore, CA 94550
}

\begin{abstract}
Solid Phase Microextraction (SPME) has been used to sample nonnuclear materials for analysis by gas chromatography-mass spectrometry (GC/MS). This report summarizes progress in the areas of individual materials' outgassing signatures, microcompatibility tests and analysis of polar analytes.
\end{abstract}

\section{Introduction}

Solid Phase Microextraction (SPME) has been used to sample nonnuclear materials for analysis by gas chromatography-mass spectrometry (GC/MS). Outgassing of compounds that may be incompatible with other weapon materials is a potentially significant factor in system aging and reliability, and SPME is ideal for the collection of trace levels of volatile and semi-volatile organic outgassing species. Laboratory experiments were carried out with the goal of utilizing SPME to non-intrusively collect and interpret trace outgas signatures from organic and high explosive (HE) components within the weapon headspace to help establish lifetimes, identify material aging mechanisms and potential incompatibilities, and to detect contamination. These experiments include small and large scale compatibility tests, collection of individual material signatures, and evaluation of SPME for polar analytes. Relevant data is fed into a mass spectral deconvolution library that is being developed concurrently. This report will summarize progress in FY04 in the areas outlined below.

Individual Material Signatures: In order to construct a database of outgassing signatures of individual organic and polymeric weapon components, samples were collected and prepared for SPME GC/MS analysis. An awareness of material specific outgassing species is needed in order to identify baseline 
outgassing characteristics. This information should also be a factor in the selection of new or reformulated materials for system rebuilds. In most cases, outgassing species of intact and/or non-defective materials are inert or present in negligible amounts, but the sensitivity of SPME allows the early detection of undesired volatile compounds.

Microcompatibility tests: Compatibility tests with small amounts of materials (a.k.a. microcompatibility tests) are normally conducted with two materials per sample vial followed by aging under different conditions. These types of compatibility tests are designed to flag potentially incompatible materials by identifying degradation products not found in the outgas signatures of the individual materials. Previous work in this area focused on the interaction of polysulfone with select materials and composites (UCRL-TR-206891). Additional tests were carried out to evaluate the interactions of other system materials that had not been studied in FY03.

SPME of polar analytes: Finally, SPME is being evaluated for the identification of polar analytes such as alcohols and carboxylic acids that may be present in some weapon materials. Such compounds could be present as synthesis or processing byproducts, or as degradation products, and this class of compounds has not been targeted in earlier SPME work. The typical SPME-GC setup for LLNL experiments has involved a SPME fiber and GC column combination that is optimized for the majority of anticipated headspace species, which are non-polar to slightly polar compounds (e.g. siloxanes, hydrocarbons); however, polar compounds such as alcohols and carboxylic acids are not readily observed in this analytical setup. The search for polar outgassing products offers an opportunity to collect additional data on the state of weapon materials and thereby form a more complete picture of total outgassing behavior.

\section{Experimental}

General sample preparation for SPME-GC/MS analysis: Materials are prepared for SPME headspace sampling by placing either the individual material or two materials (usually 10-100 mg) in a headspace vial that is sealed under 
nitrogen. Samples are aged at room temperature or $70^{\circ} \mathrm{C}$ for two weeks prior to analysis.

Automated analysis conditions: Samples are analyzed by SPME GC/MS using an automated system under the following conditions: $75 \mu \mathrm{m}$ CarboxenPDMS SPME fiber, conditioned for $20 \mathrm{~min}$ at $260^{\circ} \mathrm{C}$; headspace sampled at $50^{\circ} \mathrm{C}$ for $5 \mathrm{~min}$ and injected into the $\mathrm{GC}$ for $1 \mathrm{~min}$ at $250^{\circ} \mathrm{C}$. The Agilent $6890 \mathrm{GC}$ is set for splitless injection, purge @ 0.5 min, using a Restek RTX5-MS column (30 $\mathrm{m}, 0.25 \mathrm{~mm}$ ID, $0.25 \mu \mathrm{m}$ film) with a $1.0 \mathrm{~mL} / \mathrm{min}$ constant flow of helium. The 20 min run has the following temperature profile: $40^{\circ} \mathrm{C} / 2 \mathrm{~min}, 15^{\circ} \mathrm{C} / \mathrm{min}$ to $300^{\circ} \mathrm{C}$, hold $0.67 \mathrm{~min}$. An Agilent 5973 mass spectrometer scans the mass range from 20-450 at a rate of $1.75 \mathrm{scans} / \mathrm{sec}$ with a filament delay of $2.75 \mathrm{~min}$.

Polar SPME conditions: Headspace samples are collected manually under the following conditions: $85 \mu \mathrm{m}$ Polyacrylate SPME fiber, conditioned for $30 \mathrm{~min}$ at $300^{\circ} \mathrm{C}$; headspace sampled at $50^{\circ} \mathrm{C}$ for $20 \mathrm{~min}$ and injected into the $\mathrm{GC}$ for $1 \mathrm{~min}$ at $250^{\circ} \mathrm{C}$. The Hewlett-Packard $6890 \mathrm{GC}$ is set for splitless injection, purge @ 0.75 min, using a Supelco Nukol column (15 m, 0.25 mm ID, $0.25 \mu \mathrm{m}$ film) with a $2.0 \mathrm{~mL} / \mathrm{min}$ constant flow of helium. The $17 \mathrm{~min}$ run has the following temperature profile: $40^{\circ} \mathrm{C} / 2 \mathrm{~min}, 15^{\circ} \mathrm{C} / \mathrm{min}$ to $220^{\circ} \mathrm{C}$, hold $3.00 \mathrm{~min}$. A Hewlett-Packard 5973 mass spectrometer scans the mass range from $35-500$ at a rate of $1.63 \mathrm{scans} / \mathrm{sec}$ with a filament delay of $2.00 \mathrm{~min}$.

\section{Results and Discussion}

Individual Materials Signatures: The collection of headspace signatures of

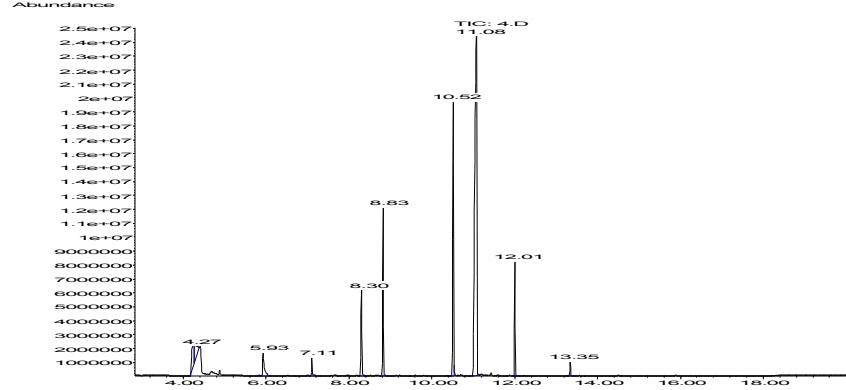

Figure 1. Gas chromatogram of SPME headspace sample of syntactic polysulfide individual weapon materials was carried out on an ongoing basis in FY04. The materials are listed in Table 1 in the appendix. A gas chromatogram of syntactic polysulfide is shown in Figure

1. The major outgassing 
product is 1,3,6,7-dioxadithionane (RT $11.08 \mathrm{~min}$ ), a known decomposition product of the polysulfide (Ellerstein, S.M.; Bertozzi, E.R. Encyclopedia of Chemical Technology, $3^{\text {rd }}$ Ed., Vol. 18, 1982, pp 814-831). This is an example of the type of information that can prove valuable in attributing headspace species to specific materials.

Microcompatibility Tests: Microcompatibility tests were carried out on the materials shown in Table 2 in the appendix. For this set of samples, no significant incompatibilities were observed. Figure 2 shows the gas chromatograms of urethane 7200, S5370, and urethane/S5370. As shown in the figure, the two largest peaks in the

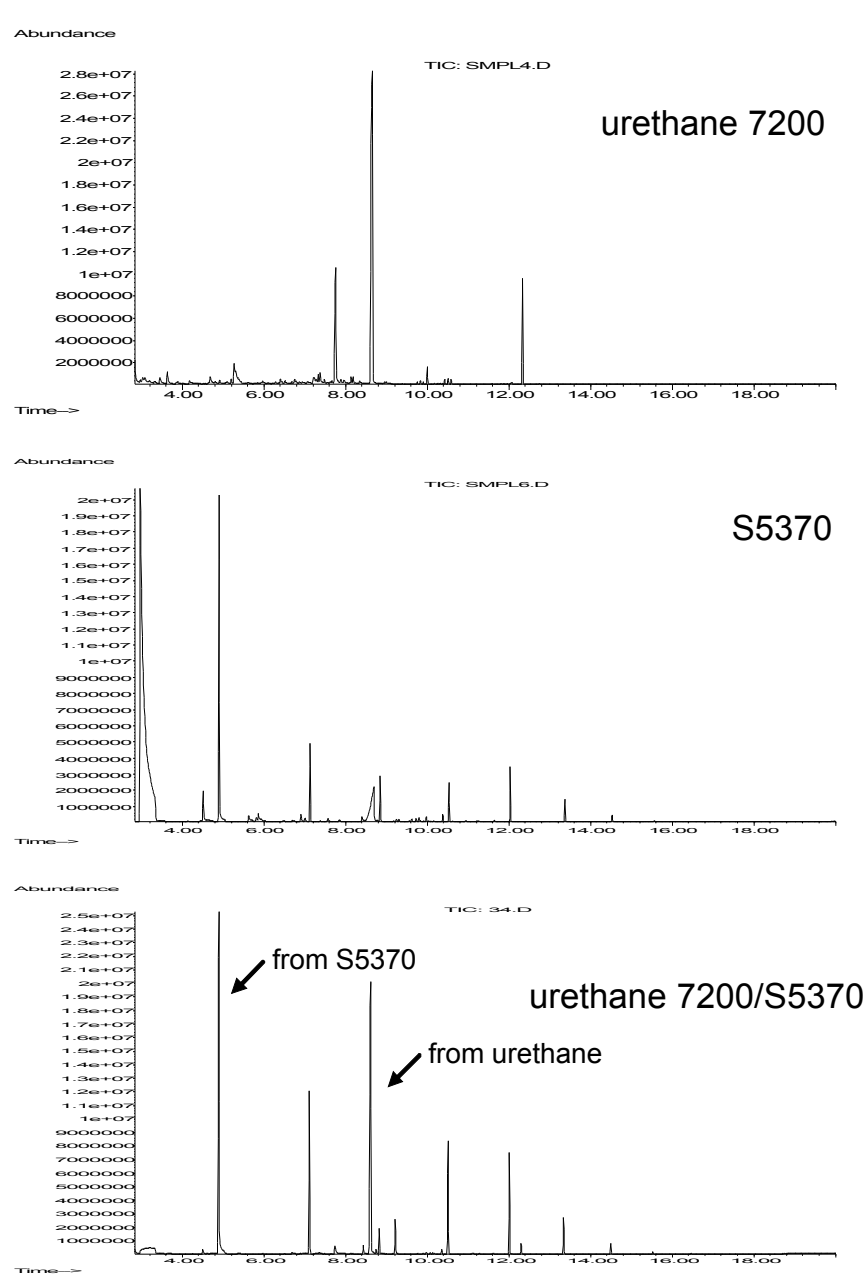

Figure 2. Gas chromatograms of urethane 
chromatogram are from the S5370 and urethane 7200 , and the other visible peaks are background siloxanes.

Ongoing materials aging and compatibility tests (MAC-1) carried out at Sandia/CA have identified some potential materials of interest, and these will be studied in more detail in FY05. Future microcompatibility tests will focus on materials that display higher levels of outgassing and/or are more sensitive to other species known to be present in the weapon headspace. Finally, new or reformulated materials will be subjected to headspace analysis and compatibility testing.

SPME of polar analytes: Outgassing analysis of the materials listed in Table 3 in the appendix was carried out using a polar polyacrylate SPME fiber and a polar GC column. While most materials did not exhibit significant polar outgassing products, there were some cases where obvious differences were observed in the polar vs nonpolar fibers/columns. Figure 3 shows the different data obtained for a standard polar test mix using columns designed for polar or nonpolar analytes. The polar column leads to strong signals from polar analytes

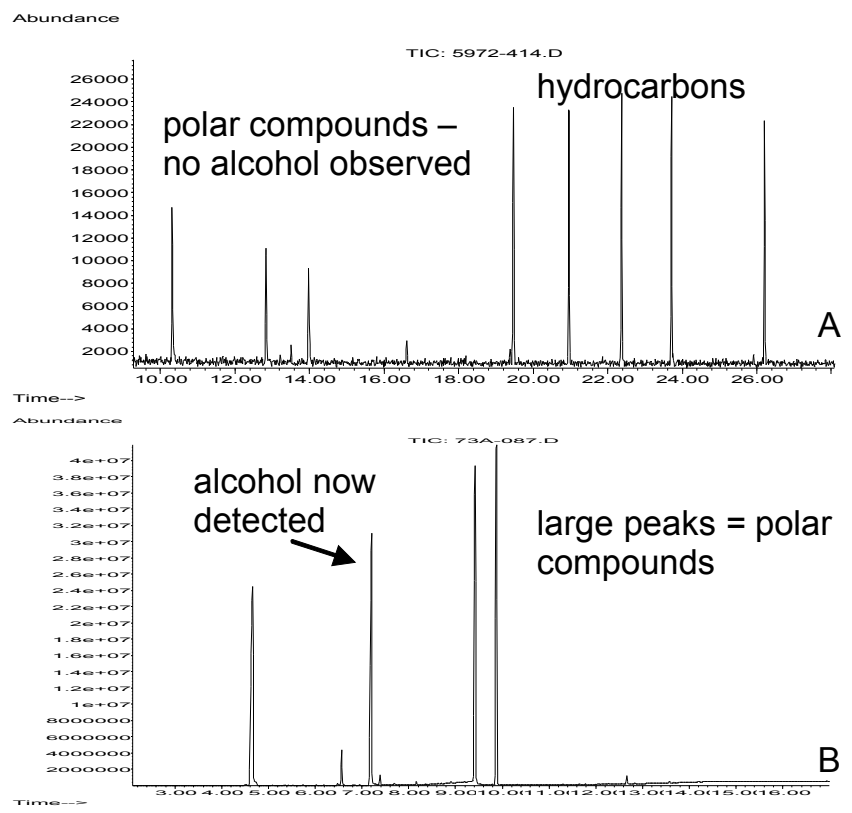

Figure 3. SPME headspace samples of polar test mix ( $A=$ RTX5-MS column; $B=$ Nukol column) 
including 1-octanol, which is not observed on the nonpolar column. The most striking example yet observed in initial studies of actual weapon materials is shown in Figure 4 where the presence of benzyl alcohol is detected in removable

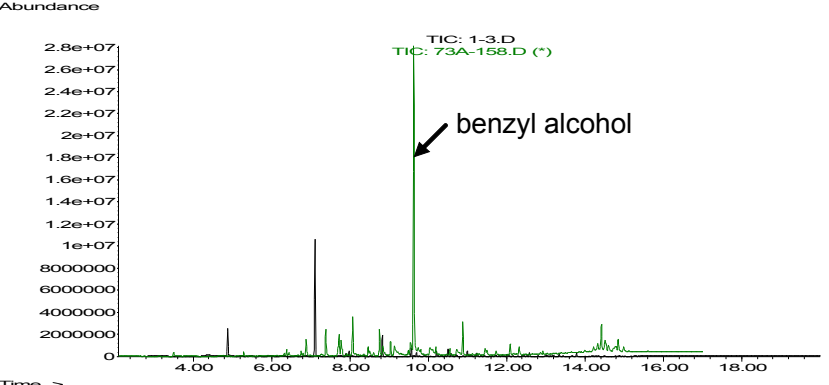

Figure 4. Overlay of chromatograms of epoxy foam (REF308). Using the non-polar column, the benzyl alcohol signal virtually disappears in the baseline. Researchers at Sandia believe the benzyl alcohol is probably a minor contaminant in the solvent used during the foam processing, and it is unlikely that benzyl alcohol is present in high enough quantities to be a concern. These early experiments, however, serve to highlight the potential for collecting additional data by focusing on polar analytes.

\section{Conclusions}

SPME continues to show its usefulness in directed stockpile work. In addition to expanding on work initiated in FY03, we have begun exploring other applications including collection of polar analytes and analysis of large scale compatibility tests such as Sandia's MAC-1 test. SPME GC/MS remains one of the best techniques for the non-destructive analysis of trace outgassing signatures from weapon materials, and it offers the flexibility of tailoring the collection and separation media for specific classes of target analytes. The Weapon Materials Compatibility and Aging group will continue to take advantage of SPME while working to improve and expand its utility in directed stockpile work. 


\section{Appendix}

Table 1. Individual Materials - SPME Headspace Analysis

\begin{tabular}{|l|l|}
\hline Material & Folder \\
\hline 3M 465 adhesive & $040621 . \mathrm{s}$ \\
\hline APC 300 & $040409 . \mathrm{s}$ \\
\hline Butyl Rubber & $040617 . \mathrm{s}$ \\
\hline DC745U & $040621 . \mathrm{s}$ \\
\hline FM123 & $040617 . \mathrm{s}$ \\
\hline FPC461 & $040621 . \mathrm{s}$ \\
\hline Halthane & $040409 . \mathrm{s}$ \\
\hline Honeycomb & $040409 . \mathrm{s}$ \\
\hline Kapton cable & $040617 . \mathrm{s}$ \\
\hline Kel-f 800 & $040409 . \mathrm{s}$ \\
\hline Loctite A & $040621 . \mathrm{s}$ \\
\hline Loctite EV & $040621 . \mathrm{s}$ \\
\hline LW520 & $040617 . \mathrm{s}$ \\
\hline Nylon sleeve & $040621 . \mathrm{s}$ \\
\hline Polysulfone & $040617 . \mathrm{s}$ \\
\hline Polyurethane & $040409 . \mathrm{s}$ \\
\hline S5370 & $040106 . \mathrm{s}$ \\
\hline Sylgard 184 & $040409 . \mathrm{s}$ \\
\hline Syntactic polysulfide & $041013 . \mathrm{s}$ \\
\hline TPX & $040409 . \mathrm{s}$ \\
\hline Urethane 7200 & $040106 . \mathrm{s}$ \\
\hline Viton A & $041013 . \mathrm{s}$ \\
\hline
\end{tabular}


Table 2. Materials subjected to microcompatibility tests (Data for completed tests in folders $040723 . s, 040811 . s$ \& 040903A.s; Pending tests indicated with X)

\begin{tabular}{|c|c|c|c|c|c|c|c|c|c|c|c|c|c|c|c|c|c|c|c|c|c|}
\hline & $\begin{array}{l}\varangle \\
\stackrel{\square}{0} \\
\stackrel{0}{>}\end{array}$ & $\begin{array}{r}\stackrel{P}{0} \\
\text { 怘 } \\
\leftrightarrow\end{array}$ & 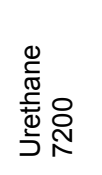 & 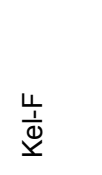 & $\begin{array}{l}\overline{0} \\
\underset{x}{x} \\
0\end{array}$ & 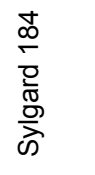 & 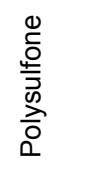 & \begin{tabular}{l}
$\bar{o}$ \\
\multirow{0}{0}{} \\
$\frac{1}{4}$
\end{tabular} & $\sum_{\text {I }}^{\times}$ & $\stackrel{\hat{D}}{\Sigma}$ & 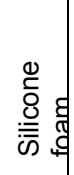 & 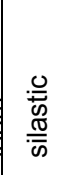 & 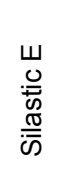 & 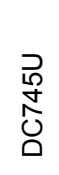 & 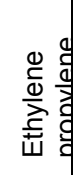 & 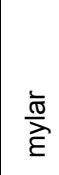 & 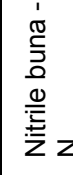 & 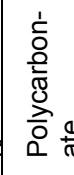 & 品 & $\underset{r}{\stackrel{Q}{r}}$ & 產 \\
\hline \multicolumn{22}{|l|}{ Viton A } \\
\hline S5370 & DONE & & & & & & & & & & & & & & & & & & & & \\
\hline Urethane 7200 & DONE & DONE & & & & & & & & & & & & & & & & & & & \\
\hline Kel-F & DONE & DONE & DONE & & & & & & & & & & & & & & & & & & \\
\hline OXY461 & DONE & DONE & DONE & DONE & & & & & & & & & & & & & & & & & \\
\hline Sylgard 184 & DONE & DONE & DONE & DONE & DONE & & & & & & & & & & & & & & & & \\
\hline Polysulfone & DONE & DONE & DONE & DONE & DONE & DONE & & & & & & & & & & & & & & & \\
\hline FPC461 & DONE & DONE & DONE & DONE & DONE & DONE & DONE & & & & & & & & & & & & & & \\
\hline HMX & $\mathrm{X}$ & $X$ & $X$ & $X$ & $X$ & $X$ & $X$ & $X$ & & & & & & & & & & & & & \\
\hline M97 & $X$ & $X$ & $X$ & $X$ & $X$ & $X$ & $X$ & $X$ & $X$ & & & & & & & & & & & & \\
\hline Silicone foam & $X$ & $X$ & $X$ & $X$ & $X$ & $X$ & $X$ & $X$ & $X$ & $X$ & & & & & & & & & & & \\
\hline Silastic & $\mathrm{X}$ & $\mathrm{X}$ & $\mathrm{X}$ & $\mathrm{X}$ & $\mathrm{X}$ & $\mathrm{X}$ & $\mathrm{X}$ & $\mathrm{X}$ & $\mathrm{X}$ & $\mathrm{X}$ & $X$ & & & & & & & & & & \\
\hline Silastic E & $\mathrm{X}$ & $X$ & $X$ & $X$ & $X$ & $\mathrm{X}$ & $X$ & $X$ & $\mathrm{X}$ & $\mathrm{X}$ & $X$ & $X$ & & & & & & & & & \\
\hline DC745U & $\mathrm{X}$ & $X$ & $X$ & $X$ & $\mathrm{X}$ & $\mathrm{X}$ & $\mathrm{X}$ & $\mathrm{X}$ & $\mathrm{X}$ & $\mathrm{X}$ & $\mathrm{X}$ & $X$ & $X$ & & & & & & & & \\
\hline Ethylene propylene diene & $X$ & $X$ & $X$ & $X$ & $X$ & $X$ & $X$ & $X$ & $X$ & $\mathrm{X}$ & $X$ & $X$ & $\mathrm{X}$ & X & & & & & & & \\
\hline Mylar & $\mathrm{X}$ & $X$ & $X$ & $X$ & $\mathrm{X}$ & $\mathrm{X}$ & $\mathrm{X}$ & $\mathrm{X}$ & $X$ & $\mathrm{X}$ & $\mathrm{X}$ & $X$ & $X$ & $\mathrm{X}$ & $\mathrm{X}$ & & & & & & \\
\hline Nitrile buna-N & $\mathrm{X}$ & $\mathrm{X}$ & $X$ & $X$ & $X$ & $X$ & $X$ & $X$ & $X$ & $X$ & $X$ & $X$ & $X$ & $X$ & $X$ & $X$ & & & & & \\
\hline Polycarbonate & $X$ & $X$ & $X$ & $X$ & $X$ & $X$ & $X$ & $X$ & $X$ & $X$ & $X$ & $X$ & $X$ & $X$ & $X$ & $X$ & $X$ & & & & \\
\hline DC281 & $X$ & $X$ & $X$ & $X$ & $X$ & $X$ & $X$ & $X$ & $X$ & $X$ & $X$ & $X$ & $X$ & $X$ & $x$ & $X$ & $X$ & $X$ & & & \\
\hline TATB & $X$ & $X$ & $X$ & $X$ & $X$ & $X$ & $X$ & $X$ & $X$ & $X$ & $X$ & $X$ & $X$ & $X$ & $X$ & $X$ & $X$ & $X$ & $X$ & & \\
\hline RDX & $X$ & $X$ & $X$ & $X$ & $X$ & $X$ & $X$ & $X$ & $X$ & $X$ & $X$ & $X$ & $X$ & $X$ & $X$ & $X$ & $X$ & $X$ & $X$ & X & \\
\hline
\end{tabular}


Table 3. Materials sampled with polar SPME fiber and Nukol column.

\begin{tabular}{|l|l|}
\hline Material & Data Folder \\
\hline Polyurethane & $0404 . s$ \\
\hline Sylgard 184 & $0404 . s$ \\
\hline Polysulfone & $0404 . s$ \\
\hline TPX & $0404 . s$ \\
\hline Halthane & $0404 . s$ \\
\hline Viton A & $0404 . s$ \\
\hline Kel-F & $0404 . s$ \\
\hline APC & $0404 . s$ \\
\hline Honeycomb & $0404 . s$ \\
\hline REF 308 & $0406 . s$ \\
\hline RSF 200 & $0406 . s$ \\
\hline Polysulfide & $0406 . s$ \\
\hline Syntactic polysulfide & $0406 . s$ \\
\hline Urethane 7200 & $0406 . s$ \\
\hline Loctite A and EV & $0406 . s$ \\
\hline
\end{tabular}

